Published in final edited form as:

Curr Gastroenterol Rep. 2013 September ; 15(9): 344. doi:10.1007/s11894-013-0344-2.

\title{
Opioid-Induced Bowel Dysfunction
}

\author{
Gyanprakash A. Ketwaroo, MD, MSc, \\ Beth Israel Deaconess Medical Center, 330 Brookline Ave, Boston MA 02215, USA. \\ 617-667-2136. 617-667-1234 (fax)
}

Vivian Cheng, MPH, MS, and

Beth Israel Deaconess Medical Center, 330 Brookline Ave, Boston MA 02215, USA.

617-667-0682

Anthony Lembo, MD

Beth Israel Deaconess Medical Center, 330 Brookline Ave, Boston MA 02215, USA.

617-667-2138. 617-667-1171 (fax)

\begin{abstract}
Opioid-induced bowel dysfunction (OIBD) is a potentially debilitating side effect of chronic opioid use. It refers to a collection of primarily gastrointestinal motility disorders induced by opioids, of which opioid-induced constipation (OIC) is the most common. Management of OIBD is difficult, and affected patients will often limit their opioid intake at the expense of experiencing more pain, to reduce the negative impact of OIBD on their quality of life. Effective pharmacologic therapy for OIC is considered an unmet need and several agents have recently been given priority review and approval for OIC. Furthermore, multiple agents currently in development show promise in treating OIC without significant impact on analgesia or precipitation of withdrawal symptoms. The approval and availability of such medications would represent a significant improvement in the management of OIC and OIBD in patients with chronic pain.
\end{abstract}

\section{Keywords}

Constipation; opioid; bowel dysfunction

\section{INTRODUCTION}

Chronic use of opioids to manage pain is common in clinical practice [1-3]. In the United States, opioid use has increased sharply over the past decade and it is estimated that approximately $3 \%$ of the population receives long-term opioid therapy for chronic noncancer pain [4]. Among patients who require chronic opioids, the balance between the incidence and severity of side effects and analgesia plays an important role in the success or

Correspondence to: Gyanprakash A. Ketwaroo.

Conflict of Interest

Gyanprakash A. Ketwaroo, Vivian Cheng, and Anthony Lembo declare that they have no conflict of interest

Human and Animal Rights and Informed Consent

This article does not contain any studies with human or animal subjects performed by any of the authors. 
failure of adequate pain management programs. The gastrointestinal (GI) tract is a particularly important source of opioid-related side effects, collectively termed opioidinduced bowel dysfunction (OIBD). Although opioid-induced constipation (OIC) is the most common side effect of opioids, other symptoms related to OIBD include nausea, vomiting, and dyspepsia [5]. Patients taking opioids may also suffer from decreased gastric emptying (often leading to gastroesophageal reflux and heartburn), abdominal cramping, spasm, and bloating [6-9]. Consequently, OIBD can have a dramatic negative impact on quality of life, both as a result of the direct, unwanted effects of opioids as well as a result of side effectinduced limitations of adequate dosing of narcotic analgesics.

\section{FREQUENCY AND IMPACT OF OPIOID-INDUCED CONSTIPATION}

In a survey of patients with non-cancer pain taking a median daily dose of $127.5 \mathrm{mg}$ morphine-equivalent (range 7.5-600 mg) the most commonly reported GI side effect was constipation (46.9\%; $95 \%$ CI 36.8-57.3), followed by gastro-esophageal reflux disease (33\%; $95 \%$ CI 23.5-42.9), nausea (27\%; $95 \%$ CI 17.2-35.3), and vomiting (9\%; $95 \%$ CI 17.2-35.3) [10]. Chronic abdominal pain was also common (58.2\%; $95 \%$ CI 53.2-73.9) and was associated with reduction in quality of life. A Cochrane systematic review of adults on opioids for non-cancer pain for at least 6 months found $22.0 \%$ (95\% CI, 15.2-32.8) of patients discontinuing therapy due to adverse effects [11].

A multi-national study involving 322 patients taking oral opioids and laxatives found that OIC was most often characterized as severe, with $45 \%$ reporting $<3$ bowel movements per week [12]. Importantly, nearly a third of patients altered their doses of opioid therapy in an attempt to mitigate the constipating side effects of these medications.

\section{PATHOPHYSIOLOGY OF OPIOID-INDUCED GASTROINTESTINAL EFFECTS}

The activity of opioids in the gut is mediated by $\mu-, \delta$-, and $\kappa$-opioid receptors, the distribution of which varies within the layers of the GI tract. In particular, $\mu$-opioid receptors — through which most opioid analgesics function [13] — are present on the myenteric and submucosal neurons and on immune cells in the lamina propria. These receptors are present in the highest concentrations in the stomach and proximal colon $[6,14]$. Endogenous opioids, such as met-enkephalin, leu-enkephalin, $\beta$-endorphin, and dynorphin [15], inhibit both propulsive motor and secretory activities [6].

Exogenous opioids cause constipation through multiple mechanisms. Through their effects on enteric neurons, opioids delay intestinal transit by stimulating nonpropulsive motility, increasing intestinal tone, and stimulating the pyloric and ileocecal sphincters [16]. Opioid agonists also stimulate fluid absorption in the gut by increasing contact time for absorption and stimulating mucosal sensory receptors. These agents also appear to inhibit chloride secretion by suppressing the excitation of cholinergic secretomotor neurons in the enteric nervous system [16]. Genetic polymorphisms and diversity may play a role in variation of people's responses to opioids [17]. Such genetic diversity may impact the potential for developing OIBD, though the evidence for this remains limited. 


\section{MANAGEMENT OPTIONS FOR OPIOID-INDUCED CONSTIPATION}

Since the dose that produces constipation is generally only $25 \%$ of that required to provide adequate analgesia, simple opioid dose reduction is generally not an effective option for the management of OIC. Thus, alternative options for managing this condition must be explored.

\section{Opioid rotation}

Opioids have slightly different propensities to cause constipation in individual patients. Switching opioids, or "opioid rotation", may be used as a strategy to relieve OIC or other adverse effects. A prospective trial enrolled 118 cancer patients at a single institution [18], who underwent opioid switching due to an unacceptable balance between analgesia and opioid-induced adverse effects. Eighty-one percent of substitutions were successful in finding a more acceptable balance between analgesia and adverse effects after the first switch in opioids and an additional $6 \%$ responded after a second switch in therapy. The mean time required to identify an appropriate dose after switching was 3.2 days and the time to hospital discharge was directly related to the time needed to achieve dose stabilization. While this small trial suggests that algorithm-guided opioid rotation can be effective, prospective randomized trials regarding the efficacy and cost of this strategy are lacking and caution is necessary as equianalgesic doses can vary from person to person.

\section{Novel opioids with less constipation}

Few studies have directly compared the prevalence of GI side effects among opioids. Four controlled studies, however, found that transdermal fentanyl was associated with less frequent laxative use compared with morphine [19-22]. Tapentadol is a novel $\mu$-opioid agonist that also inhibits norepinephrine, which is believed to augment its analgesic activity [23]. In a trial conducted in patients with lower back pain, tapentadol extended release 100$250 \mathrm{mg}$ twice daily and oxycodone $\mathrm{HCl}$ controlled release $20-50 \mathrm{mg}$ twice daily were both effective in controlling pain; however, the GI side effect profile of tapentadol was substantially better than that of oxycodone [24]. Similar results were seen in trials conducted in patients with moderate-to-severe chronic joint and back pain [25-28].

\section{Adjunctive pharmacologic treatment}

Laxatives-Conventionally, OIC is first approached through the use of laxatives such as osmotic (e.g., polyethylene glycol, magnesium) and stimulant laxatives (e.g., senna, bisacodyl). However, only about $50 \%$ of patients experience satisfactory relief using this strategy [29, 30]. For this reason, treatment with laxatives often requires frequent dose adjustments, combination therapy, and laxative switching before achieving satisfactory results.

Lubiprostone-Lubiprostone, a chloride channel type 2 activator, is the only oral medication approved by the Food and Drug Administration (FDA) for use in chronic constipation and irritable bowel syndrome (IBS) with constipation. It was recently approved for treating OIC at a dose of $24 \mathrm{mcg}$ twice daily, based on three Phase 3 randomized doubleblind controlled trials involving patients with chronic non-cancer pain [31]. 
One Phase 3 trial, Study 1, was conducted in 431 patients with non-cancer-related pain treated with any opioid agonist except methadone. Subjects were randomized to lubiprostone $24 \mathrm{mcg}$ twice daily or placebo for 12 weeks. This study's primary endpoint was the spontaneous bowel movement (SBM) response rate, defined as 3 or more SBMs per week for at least 9 weeks and at least 1 additional SBM per week over the mean at baseline. At the end of the 12-week treatment period, significantly more patients taking lubiprostone were "overall responders" compared with those receiving placebo ( 27.1 vs. $18.9 \%, p=0.03)$ [31].

In the other two identically designed Phase 3 trials, patients with chronic non-cancer pain on chronic opioid therapy including methadone received lubiprostone $24 \mathrm{mcg}$ twice daily or placebo for 12 weeks [31]. The primary endpoint was the mean change from baseline in the frequency of SBMs at week 8. In one study $(n=418)$, there was a statistically significant treatment difference of 0.9 SBM (3.3 vs. 2.4 for the lubiprostone and placebo treated groups, respectively; $p=0.004)$. Furthermore, there was a higher proportion of "overall responders" (3 or more SBMs per week for at least 9 weeks and at least 1 additional SBM per week over the mean at baseline),in the lubiprostone-treated group compared to the placebo group (24.3 vs. $15.3 \%$, respectively). In the third study $(n=451)$, there was no statistically significant change in SBM at week 8 for the lubiprostone treated group compared with placebo [31].

Among all three studies $(n=1,492)$, the most common adverse events in the lubiprostone group compared with the placebo group were nausea (11 vs. $5 \%$ ), diarrhea ( 8 vs. $2 \%$ ), and abdominal pain (4 vs. $1 \%$ ). There were no serious adverse events [31].

Naloxone-Naloxone, a competitive antagonist at opioid receptors with much higher affinity for $\mu$-receptors than both $\kappa$ - and $\delta$-receptors, has been used to reverse OIC. Naloxone has a low oral systemic bioavailability due to extensive first pass-metabolism. Nevertheless, it is still widely distributed throughout the body and central nervous system, and when used at even a low dosage (2-4 mg three times daily) analgesia reversal and induction of opioid withdrawal symptoms can occur [32]. Combining oxycodone with naloxone has been shown to improve symptoms of constipation without significant reduction in analgesia for up to 52 weeks [33]. In a recent randomized control trial of 185 patients with chronic cancer pain, oxycodone/naloxone prolonged-release tablets were as effective as prolonged-release oxycodone in maintaining analgesia with significantly less constipation symptoms [34].

Methylnaltrexone-Methylnaltrexone, a quaternary ammonium derivative of naltrexone, is largely restricted to the periphery due to poor lipid solubility and is thus less likely than naloxone to reverse analgesia and induce opioid withdrawal symptoms [35]. It can be administered intravenously, subcutaneously, and orally, and all forms have been associated with a reduction in OIC. Only the subcutaneous administration form of methylnaltrexone is FDA approved for the treatment of OIC in advanced disease.

When administered intravenously, infusion of methylnaltrexone has been shown to reverse the constipation induced by methadone, increasing stool frequency and decreasing orocecal transit time [36, 37]. Subcutaneous methylnaltrexone was examined in 133 patients with 
advanced illness and opioid-induced constipation that had not responded to $\geq 3$ days of laxatives [38]. In the methylnaltrexone group, $48 \%$ of patients had a bowel movement within $4 \mathrm{~h}$ after the first study dose compared to $15 \%$ in the placebo group, and $52 \%$ had a bowel movement within $4 \mathrm{~h}$ after $\geq 2$ of the first four doses, compared with $8 \%$ in the placebo group ( $p \leq 0.001$ for both comparisons; Fig. 1). The response rate remained consistent throughout a 3-month extension trial. Evidence of withdrawal mediated by central nervous system opioid receptors or changes in pain scores was not observed. Abdominal pain and flatulence were the most common adverse events. Subsequent studies have confirmed a similar efficacy of subcutaneous methylnaltrexone at a dose of $12 \mathrm{mg}$ either once daily or every other day in treating OIC [39-41]. Subcutaneous methylnaltrexone was approved by the FDA in 2008 for opioid-induced constipation in patients with advanced illness who are receiving palliative care, when response to laxative therapy has not been sufficient [42]. It is usually dosed once every other day, but no more frequently than one dose in a 24-h period. The recommended dose of methylnaltrexone is $8 \mathrm{mg}$ for patients weighing between 38 and $62 \mathrm{~kg}, 12 \mathrm{mg}$ for patients weighing 62 to $114 \mathrm{~kg}$, and $0.15 \mathrm{mg} / \mathrm{kg}$ for patients outside these ranges.

Results from a 12-week phase 3 trial in 803 patients with chronic non-cancer pain and OIC with oral methylnaltrexone $(150,300$, or $450 \mathrm{mg}$; 4 weeks daily dosing, followed by 8 weeks PRN dosing) were recently presented [43]. Patients receiving the 300 and $450 \mathrm{mg}$ doses achieved a statistically significant higher incidence of bowel movements without the need for laxatives compared with placebo. Throughout the study, there were minimal changes from baseline in pain intensity scores, regardless of the treatment group.

Alvimopan-Alvimopan is an oral $\mu$-opioid receptor antagonist that does not cross the blood-brain barrier [44]. Alvimopan was approved by the FDA in 2008 for post-operative ileus with a Risk Evaluation and Mitigation Strategy due to an increased number of myocardial infarctions in one 12-month study. This imbalance has not been observed in other studies. While alvimopan is not approved for the management of OIC, it has been extensively studied for this indication. In one pivotal trial, 522 patients taking $230 \mathrm{mg}$ of oral morphine and with associated constipation (i.e., <3 SBMs per week), were randomized to 6 weeks of alvimopan $0.5 \mathrm{mg}$ twice daily, $1 \mathrm{mg}$ once daily, $1 \mathrm{mg}$ twice daily, or placebo. Alvimopan at all doses evaluated was associated with a significant increase in the mean number of SBMs per week over the first 3 weeks of treatment. Alvimopan was also associated with improvements in straining, stool consistency, incomplete evaluation, decreased appetite, and abdominal bloating/discomfort. In this study, the side effect profile of the $0.5 \mathrm{mg}$ twice daily dose was similar to placebo [45].

Subsequently, two large Phase 3 clinical trials have been published comparing alvimopan $0.5 \mathrm{mg}$ once daily, twice daily, or placebo for 12 weeks in non-cancer OIC [46, 47]. Only one of the two studies met the primary endpoint (i.e., the proportion of patients experiencing $\geq 3$ SBM per week over the treatment period and an average increase from baseline of $\geq 1$ SBM). Both studies showed improvement in straining, stool consistency, incomplete evacuation, and abdominal bloating/discomfort. Alvimopan did not significantly reverse opioid analgesia. 


\section{Agents under investigation}

Naloxegol (formerly known as NKTR-118) is a combination of oral naloxol, a derivative of the opioid antagonist naloxone, and a polyethylene glycol moiety, which reduces first-pass metabolism, thereby increasing bioavailability and reducing penetration into the central nervous system. The results of two Phase 3 trials (KODIAC-04 and -05) and a safety extension trial for naloxegol were recently announced, although they have not yet appeared in a peer-reviewed literature [48]. Both studies evaluated the efficacy of 12 weeks of treatment with naloxegol 12.5 and $25 \mathrm{mg}$ compared with placebo. The primary endpoint was response at 12 weeks defined as $\geq 3$ SBMs per week with a $\geq 1$ SBM increase over baseline for $\geq 9$ of 12 weeks. In KODIAC-04, both the 12.5 and $25 \mathrm{mg}$ doses of naloxegol demonstrated statistically significant results for the primary endpoint $(p=.015$ and 0.001 , respectively). In KODIAC-05, only the $25-\mathrm{mg}$ dose was statistically significant ( $p=0.021)$. Arthralgia was the only adverse event that occurred at a greater frequency in the naloxegol 25-mg arm compared to placebo.

TD-1211 is an oral multivalent inhibitor of the $\mu$-opioid receptor currently under investigation for the management of OIC. In a recent Phase 2 trial, 217 patients with noncancer OIC were randomized to one of three doses of TD-1211 $(5,10$, or $15 \mathrm{mg}$ after a lead in period of $5 \mathrm{mg}$ in all groups) or placebo for 5 weeks. All doses of TD-1211 met the primary endpoint of an increase in weekly average complete spontaneous bowel movements (CSBMs) over treatment weeks 2-5 compared to baseline. The placebo-treated group reported an increase from baseline of 0.8 CSBMs per week versus 2.5 ( $p=0.0003), 2.6$ ( $p=$ $0.001)$, and $1.5(p=0.04)$ CSBMs per week for the TD-1211-treated groups $(15,10$, and 5 $\mathrm{mg}$, respectively). The most common adverse events were abdominal pain, nausea, diarrhea, and headache and there was no adverse effect on analgesia with TD-1211 [49].

Benvenopran (CB-5945, formerly ADL5945) is another peripherally-acting $\mu$-opioid receptor antagonist under investigation for OIC. Two Phase 2 trials recently compared benvenopran with placebo in patients with non-cancer chronic pain and OIC. The primary endpoint was change in SBMs over the 4-week treatment period. Benvenopran-treated patients receiving $0.25 \mathrm{mg}$ daily and $0.25 \mathrm{mg}$ twice daily showed statistically significant increases from baseline compared to those receiving placebo daily and twice daily ( 2.58 , $3.42,1.40$, and $1.44 \mathrm{SBM}$, respectively). The most commonly reported adverse events were abdominal pain and upper respiratory tract infection. There were no changes in analgesic effect or evidence of CNS effects [50].

Prucalopride is a 5- $\mathrm{HT}_{4}$ agonist that accelerates colonic transit in healthy humans and in patients with functional constipation. It is approved in the European Union and Canada for chronic idiopathic constipation. A Phase 2 trial randomized 196 chronic non-cancer pain patients with OIC and no history of chronic constipation prior to beginning opioid therapy to either prucalopide 2 or $4 \mathrm{mg}$ or placebo for four weeks. The primary endpoint was the proportion of patients with an increase of at least $\geq 1$ CSBM per week from baseline. During the first week of treatment, both prucalopride-treated groups had a statistically significant increase in the proportion of patients reporting an increase of $\geq 1$ CSBM over the first week compared to placebo ( $43.8 \%$ of prucalopride $2 \mathrm{mg}, 50.0 \%$ of prucalopride $4 \mathrm{mg}$, and $23.4 \%$ of placebo-treated patients). When averaged over the 4 weeks, a greater proportion 
of prucalopride-treated patients reported an increase of $\geq 1$ CSBM per week from baseline ( $35.9 \%$ with prucalopride $2 \mathrm{mg}, 40.3 \%$ with prucalopride $4 \mathrm{mg}$ ) compared to placebo (23.4\%); however, these differences did not reach statistical significance. The most common adverse events observed in these trials were abdominal pain and nausea [51].

S-297995 (Naldemedine) is an oral, peripherally acting $\mu$-opioid receptor antagonist that recently completed a placebo-controlled single-ascending dose study in patients with OIC. Patients were randomized if they had chronic pain requiring $90 \mathrm{mg}$ or more morphine equivalents daily for at least 3 months. A total of 75 subjects were randomized to one of six S-297995 cohorts: $0.01,0.03,0.1,0.3,1.0$, or $3.0 \mathrm{mg}$. Preliminary results suggest that the medication was well tolerated with mild or moderate adverse events and no evidence of opioid central withdrawal and a dose-dependent increase from baseline in the number of SBMs [52].

\section{Management Guidelines}

The National Comprehensive Cancer Network (NCCN) and the American Academy of Pain Medicine (AAPM) have issued guidelines for the management of OIC [53, 54]. Both advocate prophylaxis including adequate fluid and fiber intake, laxatives, and stool softeners. While the AAPM suggest that there is insufficient evidence to recommend oral opioid antagonists to treat OIBD, the NCCN support the use of stool softeners, magnesium hydroxide, bisacodyl, lactulose, sorbitol, magnesium citrate, or polyethylene glycol, and/or the use of Fleets, saline, or tap water enemas. The NCCN also suggest opioid rotation to potentially less constipating agents, such as fentanyl or methadone, and the use of the opioid antagonist, methylnaltrexone, in severe cases.

\section{CONCLUSION}

Opioids are the foundation of the management of moderate to severe pain. Given the aging population and an increasing focus on improved management of pain, it is likely that chronic use of opioids, and OIBD, will continue to increase. For these reasons, it is critical for physicians to recognize the GI side effects of these agents and manage them appropriately. There is a broad range of management strategies for OIC with stimulant laxatives, with or without stool softeners, as the first-line pharmacologic treatment used in most patients. Unfortunately, these inexpensive and readily available agents rarely provide complete relief from OIC. In resistant patients, opioid rotation, lubiprostone, and methylnaltrexone should be considered. There have also been promising data on the benefits of investigational drugs such as benvenopran and naloxogel, among others. With current therapies and ongoing research into new pharmacological options, there is hope that eventually the impact of OIC and other GI side effects associated with chronic opioid use will be minimized while permitting adequate pain relief.

\section{References}

1. Verhaak PF, Kerssens JJ, Dekker J, Sorbi MJ, Bensing JM. Prevalence of chronic benign pain disorder among adults: a review of the literature. Pain. Sep; 1998 77(3):231-239. [PubMed: 9808348]

Curr Gastroenterol Rep. Author manuscript; available in PMC 2017 February 08. 
2. Blyth FM, March LM, Brnabic AJ, Jorm LR, Williamson M, Cousins MJ. Chronic pain in Australia: a prevalence study. Pain. Jan; 2001 89(2-3):127-134. [PubMed: 11166468]

3. Breivik H, Collett B, Ventafridda V, Cohen R, Gallacher D. Survey of chronic pain in Europe: prevalence, impact on daily life, and treatment. European journal of pain. May; 2006 10(4):287333. [PubMed: 16095934]

4. Dunn KM, Saunders KW, Rutter CM, et al. Opioid prescriptions for chronic pain and overdose: a cohort study. Annals of internal medicine. Jan 19; 2010 152(2):85-92. [PubMed: 20083827]

5. Villars P, Dodd M, West C, et al. Differences in the prevalence and severity of side effects based on type of analgesic prescription in patients with chronic cancer pain. Journal of pain and symptom management. Jan; 2007 33(1):67-77. [PubMed: 17196908]

6. Holzer P. Treatment of opioid-induced gut dysfunction. Expert opinion on investigational drugs. Feb; 2007 16(2):181-194. [PubMed: 17243938]

7. Mehendale SR, Yuan CS. Opioid-induced gastrointestinal dysfunction. Digestive diseases. 2006; 24(1-2):105-112. [PubMed: 16699269]

8. Moore RA, McQuay HJ. Prevalence of opioid adverse events in chronic non-malignant pain: systematic review of randomised trials of oral opioids. Arthritis research \& therapy. 2005; 7(5):R1046-1051. [PubMed: 16207320]

9. Pappagallo M. Incidence, prevalence, and management of opioid bowel dysfunction. Am J Surg. Nov; 2001 182(5A Suppl):11S-18S. [PubMed: 11755892]

10*. Tuteja AK, Biskupiak J, Stoddard GJ, Lipman AG. Opioid-induced bowel disorders and narcotic bowel syndrome in patients with chronic non-cancer pain. Neurogastroenterology and motility : the official journal of the European Gastrointestinal Motility Society. Apr; 2010 22(4):424-430. e496. This survey showed the high prevalence of constipation in patients on chronic opioid therapy. [PubMed: 20100280]

11. Noble M, Treadwell JR, Tregear SJ, et al. Long-term opioid management for chronic noncancer pain. Cochrane database of systematic reviews. 2010; (1):CD006605. [PubMed: 20091598]

12. Bell TJ, Panchal SJ, Miaskowski C, Bolge SC, Milanova T, Williamson R. The prevalence, severity, and impact of opioid-induced bowel dysfunction: results of a US and European Patient Survey (PROBE 1). Pain medicine. Jan; 2009 10(1):35-42. [PubMed: 18721170]

13. Pasternak GW. Molecular insights into mu opioid pharmacology: From the clinic to the bench. The Clinical journal of pain. Jan; 2010 26( Suppl 10):S3-9. [PubMed: 20026962]

14. Fickel J, Bagnol D, Watson SJ, Akil H. Opioid receptor expression in the rat gastrointestinal tract: a quantitative study with comparison to the brain. Brain research. Molecular brain research. Jun; 1997 46(1-2):1-8. [PubMed: 9191072]

15. Holzer P. Opioid receptors in the gastrointestinal tract. Regulatory peptides. Jun 5; 2009 155(1-3): 11-17. [PubMed: 19345246]

16. Camilleri M. Opioid-induced constipation: challenges and therapeutic opportunities. The American journal of gastroenterology. May; 2011 106(5):835-842. quiz 843. [PubMed: 21343919]

17. Finco G, Pintor M, Sanna D, et al. Is target opioid therapy within sight? Minerva Anestesiol. Apr; 2012 78(4):462-472. [PubMed: 22310188]

18. Mercadante S, Ferrera P, Villari P, Casuccio A, Intravaia G, Mangione S. Frequency, indications, outcomes, and predictive factors of opioid switching in an acute palliative care unit. Journal of pain and symptom management. Apr; 2009 37(4):632-641. [PubMed: 19345298]

19. Radbruch L, Sabatowski R, Loick G, et al. Constipation and the use of laxatives: a comparison between transdermal fentanyl and oral morphine. Palliative medicine. Mar; 2000 14(2):111-119. [PubMed: 10829145]

20. Ahmedzai S, Brooks D. Transdermal fentanyl versus sustained-release oral morphine in cancer pain: preference, efficacy, and quality of life. The TTS-Fentanyl Comparative Trial Group. Journal of pain and symptom management. May; 1997 13(5):254-261. [PubMed: 9185430]

21. Donner B, Zenz M, Tryba M, Strumpf M. Direct conversion from oral morphine to transdermal fentanyl: a multicenter study in patients with cancer pain. Pain. Mar; 1996 64(3):527-534. [PubMed: 8783318]

22. Payne R, Mathias SD, Pasta DJ, Wanke LA, Williams R, Mahmoud R. Quality of life and cancer pain: satisfaction and side effects with transdermal fentanyl versus oral morphine. Journal of 
clinical oncology : official journal of the American Society of Clinical Oncology. Apr; 1998 16(4): 1588-1593. [PubMed: 9552070]

23. Kress HG. Tapentadol and its two mechanisms of action: is there a new pharmacological class of centrally-acting analgesics on the horizon? European journal of pain. Sep; 2010 14(8):781-783. [PubMed: 20659810]

24. Buynak R, Shapiro DY, Okamoto A, et al. Efficacy and safety of tapentadol extended release for the management of chronic low back pain: results of a prospective, randomized, double-blind, placebo- and active-controlled Phase III study. Expert opinion on pharmacotherapy. Aug; 2010 11(11):1787-1804. [PubMed: 20578811]

25. Hersh EV, Golubic S, Moore PA. Analgesic update: tapentadol hydrochloride. Compendium of continuing education in dentistry. Oct; 2010 31(8):594-599. quiz 600, 603. [PubMed: 20960989]

26. Afilalo M, Etropolski MS, Kuperwasser B, et al. Efficacy and safety of Tapentadol extended release compared with oxycodone controlled release for the management of moderate to severe chronic pain related to osteoarthritis of the knee: a randomized, double-blind, placebo-and activecontrolled phase III study. Clinical drug investigation. 2010; 30(8):489-505. [PubMed: 20586515]

27. Galvez R, Schafer M, Hans G, Falke D, Steigerwald I. Tapentadol prolonged release versus strong opioids for severe, chronic low back pain: results of an open-label, phase $3 \mathrm{~b}$ study. Adv Ther. Mar; 2013 30(3):229-259. [PubMed: 23475406]

28. Etropolski M, Kelly K, Okamoto A, Rauschkolb C. Comparable efficacy and superior gastrointestinal tolerability (nausea, vomiting, constipation) of tapentadol compared with oxycodone hydrochloride. Adv Ther. May; 2011 28(5):401-417. [PubMed: 21494892]

29. Kurz A, Sessler DI. Opioid-induced bowel dysfunction: pathophysiology and potential new therapies. Drugs. 2003; 63(7):649-671. [PubMed: 12656645]

30. Herndon CM, Jackson KC 2nd, Hallin PA. Management of opioid-induced gastrointestinal effects in patients receiving palliative care. Pharmacotherapy. Feb; 2002 22(2):240-250. [PubMed: 11837561]

31. U.S. Food and Drug Administration, Center for Drug Evaluation and Research. [Accessed May 8, 2013] Amitiza NDA 021908 Label. Apr 19. 2013 http://www.accessdata.fda.gov/drugsatfda_docs/ label/2013/021908s011lbl.pdf

32. Liu M, Wittbrodt E. Low-dose oral naloxone reverses opioid-induced constipation and analgesia. Journal of pain and symptom management. Jan; 2002 23(1):48-53. [PubMed: 11779668]

33. Sandner-Kiesling A, Leyendecker P, Hopp M, et al. Long-term efficacy and safety of combined prolonged-release oxycodone and naloxone in the management of non-cancer chronic pain. International journal of clinical practice. May; 2010 64(6):763-774. [PubMed: 20370845]

34. Ahmedzai SH, Nauck F, Bar-Sela G, Bosse B, Leyendecker P, Hopp M. A randomized, doubleblind, active-controlled, double-dummy, parallel-group study to determine the safety and efficacy of oxycodone/naloxone prolonged-release tablets in patients with moderate/severe, chronic cancer pain. Palliative medicine. Jan; 2012 26(1):50-60. [PubMed: 21937568]

35. Foss JF. A review of the potential role of methylnaltrexone in opioid bowel dysfunction. Am J Surg. Nov; 2001 182(5A Suppl):19S-26S. [PubMed: 11755893]

36. Yuan CS. Methylnaltrexone mechanisms of action and effects on opioid bowel dysfunction and other opioid adverse effects. The Annals of pharmacotherapy. Jun; 2007 41(6):984-993. [PubMed: 17504835]

37. Yuan CS, Foss JF, O'Connor M, et al. Methylnaltrexone for reversal of constipation due to chronic methadone use: a randomized controlled trial. JAMA : the journal of the American Medical Association. Jan 19; 2000 283(3):367-372. [PubMed: 10647800]

38*. Thomas J, Karver S, Cooney GA, et al. Methylnaltrexone for opioid-induced constipation in advanced illness. The New England journal of medicine. May 29; 2008 358(22):2332-2343. This study highlighted the efficacy of one of the most useful therapeutics, subcutaneous methylnaltrexone, in treating opioid-induced constipation without increasing pain or triggering opioid withdrawal. [PubMed: 18509120]

39. Slatkin N, Thomas J, Lipman AG, et al. Methylnaltrexone for treatment of opioid-induced constipation in advanced illness patients. J Support Oncol. Jan-Feb;2009 7(1):39-46. [PubMed: 19278178] 
40. Anissian L, Schwartz HW, Vincent K, et al. Subcutaneous methylnaltrexone for treatment of acute opioid-induced constipation: phase 2 study in rehabilitation after orthopedic surgery. J Hosp Med. Feb; 2012 7(2):67-72. [PubMed: 21998076]

41. Michna E, Blonsky ER, Schulman S, et al. Subcutaneous methylnaltrexone for treatment of opioidinduced constipation in patients with chronic, nonmalignant pain: a randomized controlled study. The journal of pain : official journal of the American Pain Society. May; 2011 12(5):554-562. [PubMed: 21429809]

42. Relistor (methylnatrexone) [package insert]. Salix Pharmaceuticals, Inc; Raleigh, NC: 2012.

43. Rauck RL, Peppin JF, Israel RJ, et al. Oral Methylnaltrexone for the Treatment of Opioid-Induced Constipation in Patients with Noncancer Pain. Gastroenterology. 2012; 142(5, Supplement 1):S160.

44. Schmidt WK. Alvimopan* (ADL 8-2698) is a novel peripheral opioid antagonist. Am J Surg. Nov; 2001 182(5A Suppl):27S-38S. [PubMed: 11755894]

45. Webster L, Jansen JP, Peppin J, et al. Alvimopan, a peripherally acting mu-opioid receptor (PAMOR) antagonist for the treatment of opioid-induced bowel dysfunction: results from a randomized, double-blind, placebo-controlled, dose-finding study in subjects taking opioids for chronic noncancer pain. Pain. Jul 15; 2008 137(2):428-440. [PubMed: 18164818]

46. Jansen JP, Lorch D, Langan J, et al. A randomized, placebo-controlled phase 3 trial (Study SB-767905/012) of alvimopan for opioid-induced bowel dysfunction in patients with non-cancer pain. The journal of pain : official journal of the American Pain Society. Feb; 2011 12(2):185-193. [PubMed: 21292169]

47. Irving G, Penzes J, Ramjattan B, et al. A randomized, placebo-controlled phase 3 trial (Study SB-767905/013) of alvimopan for opioid-induced bowel dysfunction in patients with non-cancer pain. The journal of pain : official journal of the American Pain Society. Feb; 2011 12(2):175-184. [PubMed: 21292168]

48. Astra Zeneca [press release]. [Accessed November 15, 2012] AstraZeneca announces positive results from naloxegol pivotal trials in patients with opioid-induced constipation. Available at: http://www.astrazeneca.com/Media/Press-releases/Article/20121211--astrazenecaannouncestopline

49. Vickery, R., Li, Y., Schwertschlag, U., Singla, N., Webster, L., Canafax, D. TD-1211 demonstrates improvement in bowel movement frequency and Bristol Stool Scores in a phase IIb study of patients with opioid-induced constipation (OIC). 2012.

50. Techner L, Singla N, Gabriel K, Mangano R. ADL5945, a potent orally bioavailable peripheral opioid receptor antagonist, improves bowel motility w/a low incidence/severity of GI AEs in a dose-dependent manner: results of $2 \mathrm{Ph} 2$ trials in opioid-induced constipation pts (45CL242 and 45CL243). The Journal of Pain. 2012; 13(4, Suppl):S84.

51. Sloots CE, Rykx A, Cools M, Kerstens R, De Pauw M. Efficacy and safety of prucalopride in patients with chronic noncancer pain suffering from opioid-induced constipation. Dig Dis Sci. Oct; 2010 55(10):2912-2921. [PubMed: 20428949]

52. [Accessed May 08, 2013] http://www.shionogi.com/

53. National Comprehensive Cancer Network. [Accessed May 08, 2013] NCCN Clinical Practice Guidelines in Oncology (NCCN Guidelines). Available at: http://www.nccn.org/professionals/ physician_gls/pdf/pain.pdf

54. Chou R, Fanciullo GJ, Fine PG, et al. Clinical guidelines for the use of chronic opioid therapy in chronic noncancer pain. The journal of pain : official journal of the American Pain Society. Feb; 2009 10(2):113-130. [PubMed: 19187889] 
A Primary Outcomes

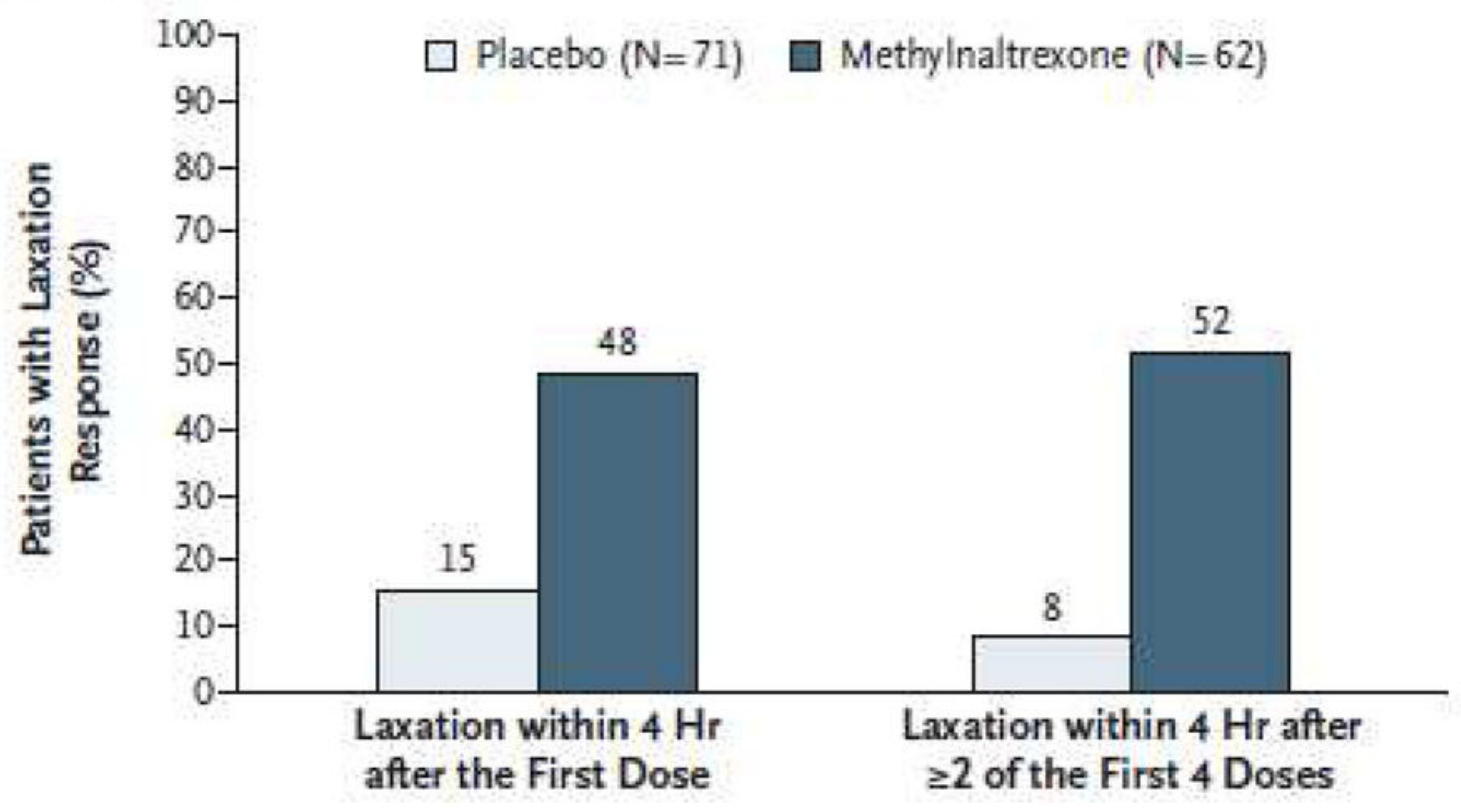

Figure 1.

Primary outcomes of a clinical trial comparing methylnaltrexone and placebo in patients with opioid-induced constipation [38] 